It will be noticed that the scale is the same for each eye. Such a method enables the optician to use a single machine for marking off the axes for the lenses of both eyes.

It is the standard notation of opticians in which all their machines are graduated, and it is into this notation that every prescription is translated by the optician before the order is passed on to his workshop.

All scientific optical and mathematical instruments are graduated in this notation.

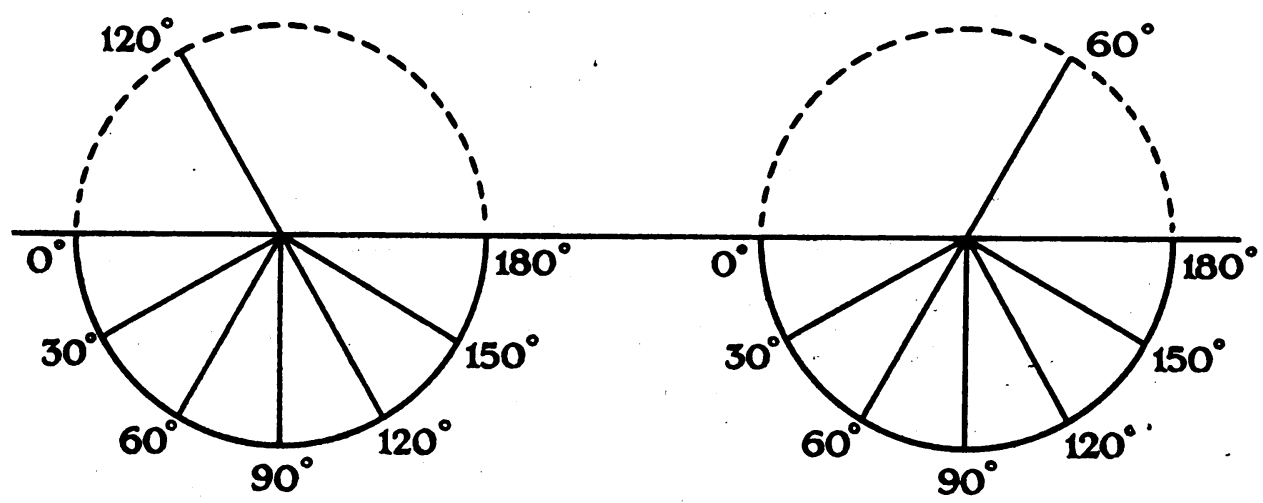

FIG. 9.

The Council, therefore, recommends the general use of this system of cylinder notation, namely:

That in which a similar notation is employed for each eye, the zero lying at the observer's left side and the scale being read below the horizontal with $90^{\circ}$ at the bottom and $180^{\circ}$ at the right side.

\title{
ANNOTATIONS
}

\section{Lectures on State Ophthalmology}

A series of lectures on State Ophthalmology was given in connection with the Royal London Ophthalmic Hospital School during the last fortnight in May. The first four were delivered at Moorfields and the last seven at the Royal Society of Medicine. The first part was concerned with the question of ophthalmology in relation to education, the opening lecture being given by Sir William Lister, who dealt with the subject from a general point of view, and set the keynote at a high pitch which was consistently maintained throughout the whole course.

Mr. Bishop Harman followed on May 18 and 19 with two 
lectures on the education of children with defective eyesight, and these were full of interesting detail showing what a prodigious amount of laborious work has been put forward by himself, in conjunction with the public bodies with which he is associated, to - enable such children to become useful members of the community.

Sir Arnold Lawson's lecture on May 20 illustrated similar efforts in connection with those blinded by accident, particularly during the war, with special reference to the work at St. Dunstan's, and enlightened his audience on the immense amount of care and forethought which is devoted to these cases.

At the Royal Society of Medicine Mr. Parsons gave three lectures, May 23, 24 and 25, introducing the subject of illumination. These were of a highly scientific order, which, if a little difficult to follow in some places, served as a salutary reminder that there are heights in ophthalmology to which many have never attained, but which at the same time should certainly create a stimulus in all of us to attempt the mastery of problems which have such an essentially practical bearing.

Mr. Leon Gaster (Secretary of Illuminating Engineering Society), in his lecture on May 26 on Practical Lighting in connection with Health, Safety and Efficiency, which was supplemented with excellent lantern slides, gave an insight into the numberless conditions where good illumination, based on scientific principles, plays such an important part.

Dr. Lister Llewellyn never fails to attract his audiences, and his lecture on Miners' Nystagmus on May 30 proved no exception to the rule; and he conclusively showed by slides, lamps, etc., how this disease is dependent on defective illumination.

Mr. Goulden on May 31 brought out by well authenticated statistics the enormous number of accidents to workmen from metallic foreign bodies, and how many of them could be avoided as well as an enormous sum saved to the State, by employing effective methods for the protection of the eyes.

Dr. T. M. Legge on June.l gave us the benefit of his unique experience gained in the factories of the nation by demonstrating the inner workings of the Workman's Compensation Act in regard to Industrial Diseases with special reference to Glass Workers' Cataract.

Altogether this course of lectures was full of interest and instruction; and the School is deeply indebted to the lecturers for their kindness in consenting so willingly to come and help to widen the scope of its teaching; the only regret we have to record is that comparatively few took advantage of such an exceptional opportunity as these lectures afforded. We hope that if any similar course is given it may be made more widely known. 